\section{View from the shore}

\section{Simon Conway Morris}

Terrestrial Invasion. An Ecophysiological Approach to the Origins of Land Animals. By Colin Little. Cambridge University Press: 1990. Pp. 304. Hbk £40, \$69.50; pbk£13.95, \$29.95.

ONE of James Lovelock's most compelling images is that of the early Earth, not as an azure jewel hanging in the blackness of space, but a dirty red smog-bound ball. Such invocations haunt us because they provide the mainspring to catapult our imaginations into the distant geological past. How, then, would a time-traveller see our planet a mere 450 million years ago, towards the end of the Ordovician? An atmosphere now cleansed by the purifying action of oxygen, deep blue oceans and polar ice-caps, but the continents themselves dun and barren, devoid of plants except, perhaps, along the fringes of the sea, where a green tideline heralded a biological revolution. The invasion of land was on, and here is a scholarly book to guide us as to how this might have been achieved.

It is a story that demands grand themes, but the reader will have to work pretty hard to find them among all the minutiae. Most striking, yet most neglected, is just how dynamic terrestrial invasion has been. For too long it has been construed as a largely Palaeozoic affair. The evidence is, however, that some animals were creeping onto land much later, in the Cretaceous or even in the Tertiary. These animals might have included the decapods and littorinacean snails. Indeed, the evolution of entire shoreline communities, especially the mangrove swamps and saltmarshes in the Cretaceous, may have done much to facilitate successful terrestrial transfer as well as those making the return journey to the sea. Ecological analogues to the mangrove swamps earlier in geological history are decidedly tenuous, so here is a timely warning about the inapplicability of uniformitarian ecology.

Meanwhile, the invasion of land probably continues. Little's suggestion that diversity of a group could be linked to time of invasion might mean that the taxonomically depauperate terrestrial amphipods may have come ashore only in the past few million years. Moreover, many of the stages of terrestrial invasion are still evident from the varying abilities of shoredwellers to cope with the rigours of the subaerial habitat. In some, relative success is marked by physiology, but simple rules of thumb are elusive and factors such as behaviour are often significant.

Another theme is to identify the main routes of invasion. Great stress is laid on physiological evidence. For example, terrestrial groups with either osmotic tolerance or high osmotic pressure are taken to indicate a direct marine origin. There are some alarming exceptions. In teleost fish, blood composition indicates a freshwater phase, although why marine representatives still carry this apparent signature is far from clear. The book is peppered with such examples of wayward ecology and physiology where no satisfac- group after group grappled with the tremendous changes that assault the terrestrial invader. These are most striking in terms of respiration, take for example the remarkable 'lung' of the crab Ocypode, and sensory perception as emphasis shifted from chemical to visual cues. But what is urgently needed is a phylogenetic perspective to this welter of ecological and physiological data. The fossil record may be appalling (although, curiously, Little does not mention the amazing finds such as those from the Devonian deposits at Gilboa), but detailed phylogenetic testing is still feasible.

So here is an excellent compilation which, if somewhat naive in its geological

\section{IMAGE UNAVAILABLE FOR COPYRIGHT REASONS}

Historical view of animals' attempts on the land.

tory explanation exists, and although Little is properly cautious there is a sense of the ad hoc about some proposals. Take also the potentially fascinating cases of failures in the invasion of land. For no obvious reason the gecarcinid crabs failed to penetrate inland, and despite their adroit subaerial excursions, the mudskippers apparently have not given rise to terrestrial lineages.

Little has much of value to say on the environments of invasion. He argues that beaches were a plausible route, with the severity of the transitional zone acting as a testing ground for would-be terrestrial aspirants. In the case of the vertebrates he casts further doubt on the time-honoured notion of proto-amphibians lurching from one drying pool to another, and suggests our terrestrial origins lay in stagnant freshwater swamps where oxygen crises imposed the need to switch to airbreathing.

This book is a rich lode of information, and it will be a shame if evolutionary biologists overlook some of its treasures. In particular, it represents a marvellous quarry for students of convergence as sections, is unrivalled in its breadth and gathering of examples. It represents serious scholarship, and will be a source to all who seek to understand how it is that the land teems with life. But the main themes in terrestrial invasion, those that must inspire the next generation, still await their biological Boswell.

Simon Conway Morris is in the Department of Earth Sciences, University of Cambridge CB2 3EQ, UK.

\section{Palaeontological paperbacks}

- Recently published by Wiley is Sleuthing Fossils. The Art of Investigating Past Life by Alan M. Cvancara. The book contains fossil identifications and describes how to collect, identify and interpret fossils. Price is $\$ 12.95$. - The Life of a Fossil Hunter by Charles $\mathrm{H}$. Sternberg was first published in 1909. Now reissued by Indiana University Press, Sternberg recounts vivid tales of the dangers of collecting dinosaur fossils in the wild west. Price is $\$ 12.95$ (hbk \$29.95).

- New from Unwin Hyman is Trace Fossils. Biology and Taphonomy, part of the series Special Topics in Palaeontology, by Richard Bromley. Price is $£ 17.95$. 